City University of New York (CUNY) CUNY Academic Works

2014

\title{
Is burnout solely job-related? A critical comment
}

\author{
Bianchi Renzo \\ Université de Neuchâtel \\ Didier Truchot \\ Université de Franche-Comté \\ Eric Laurent \\ Université de Franche-Comté \\ Romain Brisson \\ Université de Franche-Comté \\ Irvin Sam Schonfeld \\ CUNY Graduate Center
}

\section{How does access to this work benefit you? Let us know!}

More information about this work at: https://academicworks.cuny.edu/cc_pubs/300

Discover additional works at: https://academicworks.cuny.edu

This work is made publicly available by the City University of New York (CUNY).

Contact: AcademicWorks@cuny.edu 


\title{
Personality and Social Psychology
}

\section{Is burnout solely job-related? A critical comment}

\author{
RENZO BIANCHI, ${ }^{1}$ DIDIER TRUCHOT, ${ }^{1}$ ERIC LAURENT, ${ }^{1}$ ROMAIN BRISSON ${ }^{1}$ and IRVIN SAM SCHONFELD ${ }^{2}$ \\ ${ }^{1}$ University of Franche-Comté, Besançon, France \\ ${ }^{2}$ The City College of the City University of New York, New York, USA
}

Bianchi, R., Truchot, D., Laurent, E., Brisson, R. \& Schonfeld, I. S. (2014). Is burnout solely job-related? A critical comment. Scandinavian Journal of Psychology.

Within the field-dominating, multidimensional theory of burnout, burnout is viewed as a work-specific condition. As a consequence, the burnout syndrome cannot be investigated outside of the occupational domain. In the present paper, this restrictive view of burnout's scope is criticized and a rationale to decide between a work-specific and a generic approach to burnout is presented. First, the idea that a multidimensional conception of burnout implies a work-restricted scope is deconstructed. Second, it is shown that the burnout phenomenon cannot be confined to work because chronic, unresolvable stress - the putative cause of burnout - is not limited to work. In support of an integrative view of health, it is concluded that the fielddominating, multidimensional theory of burnout should abandon as groundless the idea that burnout is a specifically job-related phenomenon and define burnout as a multi-domain syndrome. The shift from a work-specific to a generic approach would allow both finer analysis and wider synthesis in research on chronic stress and burnout.

Key words: Burnout, chronic stress, generic approach, Maslach Burnout Inventory, occupational stress, scope.

Renzo Bianchi, Laboratoire de Psychologie EA 3188, Université de Franche-Comté, 30-32 rue Mégevand, 25030 Besançon CEDEX, France. Tel: +33 381665 441; fax: +33 381665 440; e-mail: dysangile@gmail.com

\section{IS BURNOUT SOLELY JOB-RELATED? A CRITICAL COMMENT}

Introduced in the mid-1970s (Freudenberger, 1974; Maslach, 1976), the burnout construct has received growing attention from researchers in psychology and psychiatry over the years, with different models of the burnout phenomenon having been developed (Schaufeli \& Enzmann, 1998). To date, Maslach's model ${ }^{1}$ (Maslach, 1982, 1998, 2003) is the leading model in the field of burnout research (Maslach, Schaufeli \& Leiter, 2001; Schaufeli \& Enzmann, 1998; Schaufeli, Leiter \& Maslach, 2009). Within this model, burnout is viewed as a work-related chronic stress syndrome made up of exhaustion, cynicism, and lack of professional efficacy (Maslach et al., 2001; Maslach, Jackson, Leiter, 1996; Weber \& Jaekel-Reinhard, 2000). Exhaustion characterizes an emotionally drained and physically used up worker. Cynicism refers to a distant and callous attitude toward one's job and especially the people with whom one interacts when working (e.g., students, clients, patients). Lastly, lack of professional efficacy includes feelings of incompetence, uselessness, and lost selfconfidence. These three dimensions are assessed with a dedicated, self-administered questionnaire, the Maslach Burnout Inventory (MBI; Maslach \& Jackson, 1981, 1986; Maslach et al., 1996), which is considered the "gold standard" for the measurement of burnout and has been used in a vast majority of studies bearing on the syndrome (Schaufeli \& Enzmann, 1998; Schaufeli et al., 2009). Despite 40 years of sustained research, gray areas subsist in the definition of burnout (Cox, Tisserand \& Taris, 2005; Shirom, 2003, 2005). Reducing this conceptual uncertainty is important if burnout research is to progress.

A central object of controversy surrounding the definition of burnout is its context-dependency (Cox et al., 2005; Farber, 1983; Freudenberger \& Richelson, 1980; Maslach \& Schaufeli, 1993; Pines \& Aronson, 1988; Pines, Aronson \& Kafry, 1981;
Schaufeli et al., 2009; Warr, 1990). Whereas some researchers posit that burnout is a work-specific phenomenon (e.g., Maslach et al., 2001; Schaufeli \& Taris, 2005), others hold that burnout is cross-domain or context-free and can occur as the result of chronic difficulties in virtually any sphere of life (e.g., Hallsten, 1993; Kristensen, Borritz, Villadsen \& Christensen, 2005; Pines, Neal, Hammer \& Icekson, 2011; Pines \& Nunes, 2003). Within Maslach's model, burnout is defined as "a crisis in one's relationship with work" (Maslach et al., 1996, p. 20) and the "work-relatedness" of burnout is presented as a distinctive feature of the construct (Maslach \& Schaufeli, 1993). For instance, the conceptual distinction between burnout and depression notably relies on the idea that burnout is job-related and situationspecific whereas depression is context-free and pervasive (Maslach et al., 2001; Schaufeli \& Enzmann, 1998). Although the work-restricted character of burnout constitutes a core tenet of Maslach's model (Schaufeli et al., 2009), the justification for the tenet remains limited (Cox et al., 2005) and has led to a circular trap. Indeed, by using an exclusively job-focused instrument as the MBI for assessing burnout, the investigator acts as if the problem of establishing burnout's scope has already been solved (Kasl, 1978; Schaufeli \& Enzmann, 1998). Empirically speaking, several studies have linked (job) burnout to non-occupational factors and situation-unspecific characteristics. Burnout has been associated with symptoms manifesting themselves in non-work situations (e.g., general cognitive impairment; Bianchi, Boffy, Hingray, Truchot \& Laurent, 2013; Sandström, Rhodin, Lundberg, Olsson \& Nyberg, 2005) as well as with personal life events (e.g., major illness; Dyrbye et al., 2006; Lopes Cardozo, Gotway Crawford, Eriksson et al., 2012) and family-related features (e.g., number of children; Ayala \& Carnero, 2013; Bekker, Croon \& Bressers, 2005; Greenglass \& Burke, 1988; Landsbergis, 1988; Leiter, 1990; Lingard, 2004; ten Brummelhuis, van der 
Lippe, Kluwer \& Flap, 2008), suggesting that purely job-focused approaches to burnout may be of limited interest. Moreover, endorsing an extended meaning of the term occupation, numerous studies have fruitfully traced burnout in the context of being a student in high school and university (Ishak, Nikravesh, Lederer, Perry, Ogunyemi \& Bernstein, 2013; May, SanchezGonzalez, Brown, Koutnik \& Fincham, 2013; Salmela-Aro, Savolainen \& Holopainen, 2009). All in all, it is unclear whether burnout should be considered a syndrome that is solely jobrelated or develops as a result of experiences in a variety of contexts.

The main aims of this paper are to (a) critically examine the way burnout's scope is conceived within Maslach's model and (b) propose a rationale to define burnout's scope, based on the consensual view that chronic stress is the fundamental cause of burnout (Maslach et al., 2001; Schaufeli \& Enzmann, 1998; Shirom, 2003; Weber \& Jaekel-Reinhard, 2000). The idea underlying this paper is that the scope of burnout is not satisfactorily defined within the field-dominating, multidimensional theory of burnout. Targeted analyses of emblematic questions were preferred over a linear literature review given the relative absence of theory regarding the scope of burnout. Rigorously defining burnout's scope is crucial to clarifying the burnout construct.

\section{MULTIDIMENSIONALITY AND CONTEXT-DEPENDENCY}

Although the issue of burnout's scope has been addressed in the past (Maslach \& Schaufeli, 1993), this has been done essentially descriptively, and the work-specific character of the burnout phenomenon has been postulated rather than demonstrated. Thus, the reason for limiting (the study of) burnout to work has long remained elusive (Schaufeli \& Taris, 2005). Recently, an explanation has been provided on this topic by contributors to Maslach's model (Schaufeli et al., 2009). In support of the idea that burnout cannot develop outside of work, it has been affirmed that a multidimensional burnout construct is by definition incompatible with the notion that burnout is a context-free phenomenon. The aim here is to show that such an assertion does not stand up to scrutiny, leaving intact the possibility of extending the burnout construct beyond the occupational domain. In order to facilitate the reader's understanding of the discussed position while not betraying any nuance in that position, a detailed quotation is provided right below.

a multi-dimensional approach as in the MBI is by definition incompatible with the notion of context-free burnout ... A retired or unemployed person may feel exhausted, but it is impossible to identify the "something" about which unemployed or retired people should feel cynical or inefficacious. Hence, arguing that burnout is a generic, context-free phenomenon goes necessarily hand in hand with a limited definition of burnout as the equivalent to exhaustion. (Schaufeli et al., 2009, p. 212)

The statement that burnout cannot be both multidimensional and context-free is problematic. Any object that is invested in by (or important for) an individual - whether related or unrelated to work - can be a "target" for cynicism and feelings of inefficacy, and there is no reason to postulate that the object in question would be less identifiably burnout-related if it is unrelated to work. Cynicism refers to an attitude of detachment and withdrawal (Schaufeli \& Taris, 2005), that is, to a disinvestment strategy that can apply to any previously invested-in object that did not provide the individual with the expected return on investment. The investment-disinvestment mechanism is both fundamental and general in the relational economy linking human beings to their (social) environment (Bourdieu, 2003) and there is no reason to confine that mechanism to work. For instance, a husband can feel cynical about his marriage that is a failure and withdraw from the marital relationship. Similarly, a father can become cynical about parenthood given an ungrateful teenage son who chronically treats him disrespectfully. The same line of reasoning can be followed with sense of inefficacy. Sense of inefficacy refers to feelings of incompetence and failed achievement (Maslach et al., 1996). Virtually anything we do can elicit such feelings in us if we chronically estimate that we do it wrong. A husband can experience a sense of inefficacy each time he is unable to manage a conjugal conflict. A father can feel inefficacious each time he fails to communicate with his rebellious teenage son. To take one of the examples provided by Schaufeli and his colleagues (2009), if chronically unemployed, one may feel cynical and inefficacious toward one's own unemployment and fruitless job search. Thus, unemployment is not per se unrelated to burnout.

The claim that a multidimensional approach to burnout is by definition incompatible with a context-free concept of burnout appears to be mistaken. Wherever there is an investment, there can be a defensive disinvestment and an emergence of cynical attitudes (Beck \& Alford, 2009; Bourdieu, 2003; Nesse, 2000; Peterson, Maier \& Seligman, 1993). In a similar vein, wherever an action is produced, a sense of inefficacy can develop, resulting in a persisting feeling that one is incompetent and unable to cope with the challenges at hand (Bandura, 1982; Beck \& Alford, 2009; Laborit, 1986; Peterson et al., 1993). Pines and Aronson (1988, p. 208), with reference to their unidimensional, "exhaustion-only," theory of burnout, pointed out that "it is possible to be a burned-out husband, a burned-out wife, or a burned-out parent". This possibility is not a priori eliminated by the adoption of a three-component definition of burnout linking exhaustion to cynicism and sense of inefficacy.

That burnout was first observed in relation to work is by no means a proof that it is specific to the occupational domain. As demonstrated in this first part of the paper, opposition to the idea that burnout may be cross-domain or context-free is not justified by an adherence to a multidimensional conception of burnout. The next section shows that an etiology-guided approach to the scope of burnout actually pleads for a multi-domain study of the syndrome.

\section{TOWARD A SOLUTION}

In order to determine whether or not burnout is a work-specific syndrome, it is necessary to consider the fundamental cause of burnout, namely, unresolvable stress (Chrousos, 2009; Chrousos \& Gold, 1992; Weber \& Jaekel-Reinhard, 2000). Interestingly, from a stress perspective, the problem of burnout's scope can be solved without speculation. Any activity able to elicit an acute 
stress response in the organism can potentially elicit a chronic activation of the stress response - this is a question of frequency and intensity - and, therefore, contribute to the development of burnout, which is conceived of as a product of chronic stress (Maslach et al., 2001; Schaufeli \& Enzmann, 1998; Shirom, 2003; Weber \& Jaekel-Reinhard, 2000). This line of reasoning leads to a conclusion that differs from that of the proponents of Maslach's model (Schaufeli et al., 2009): Burnout can only be considered a multi-domain syndrome, given that chronic stress is not a job-restricted phenomenon. This conclusion is notably in accordance with models of burnout proposed by Pines and Aronson (1988, p. 208), for whom burnout "can occur in all spheres of life that give people a sense of meaning," and Kristensen and colleagues (2005), who assessed burnout regardless of an individual's occupational status. In addition, this conclusion is consistent with findings showing that (generic) stressful and traumatic life events are associated with burnout (e.g., Mather, Blom \& Svedberg, 2014).

To date, the idea that burnout can develop outside of the workplace can only be found within some minority conceptions of burnout (e.g., Pines et al., 2011). By acknowledging that the fielddominating, multidimensional conception of burnout (Maslach et al., 2001) is compatible with a generic approach to burnout, it becomes possible to use the MBI as a basis to study burnout beyond the occupational context (e.g., parental or conjugal burnout) or within a context-independent approach. This point is critical for research advance given that (a) the MBI is by far the most widely used instrument for assessing burnout - by the end of the 1990s, the MBI was used in more than $90 \%$ of the journal articles dealing with burnout (Schaufeli \& Enzmann, 1998) - and (b) the MBI reflects a unique conception of burnout as a combination of exhaustion, cynicism, and sense of inefficacy. Our demonstration thus illuminates new avenues for integrative research on burnout, in the service of multilevel, health-promoting interventions.

\section{BURNOUT VERSUS DEPRESSION}

Before concluding, we would like to address an issue for which the problem of burnout's scope has implications. In order to distinguish burnout from depression, it has been advanced that, unlike depression, burnout is work-specific (Maslach et al., 2001). Hence, some authors have suggested that the adoption of a context-free approach to the burnout phenomenon might undermine the added value of the burnout construct with respect to the concept of depression (see Shirom, 2005). In our view, this should not be a concern for at least two reasons. First, linking the singularity of burnout to its work-relatedness is questionable given that depression can be work-related as well (Clays, De Bacquer, Leynen, Kornitzer, Kittel \& De Backer, 2007; Clumeck et al., 2009; Kahn, 2008; Rugulies, Bültmann, Aust \& Burr, 2006; Rydmark et al., 2006; Schonfeld, 2001; Siegrist, 2008; Tennant, 2001). The distinctiveness of burnout, if actual, has to lie elsewhere. Second, it is worth noting that the phenomena underlying the label of burnout - exhaustion, cynicism, and sense of inefficacy - should not be restricted to the occupational area a priori. If exhaustion, cynicism, and sense of inefficacy can be encountered in response to chronic stressors in various domains of life (e.g., in the parental or conjugal domain), these encounters should simply be recognized and assimilated, regardless of what this implies for the resolution of the burnout-depression issue. In sum, the adoption of a generic approach to burnout should not be rejected but welcomed by researchers interested in better understanding the burnout phenomenon.

\section{CONCLUSION}

Within the field-dominating, multidimensional theory of burnout (Maslach et al., 2001), burnout explicitly refers to a workspecific phenomenon. Consequently, the burnout construct cannot be applied to conditions outside of work. The present paper advanced the view that a restrictive conception of burnout is groundless. It was argued that rejecting a context-free approach to burnout by claiming that it is incompatible with a multidimensional definition of the construct is not justified. Crucially, it was affirmed that burnout's scope can be consistently defined by getting back to what lies at the heart of burnout, namely, chronic stress. On this basis, burnout cannot be confined to the occupational sphere because chronic stress is not confined to the occupational sphere. Exhaustion, cynicism, and sense of inefficacy, the usually-recognized components of burnout, can thus develop in response to chronically-occurring occupational and nonoccupational difficulties.

In Maslach's model, burnout has long been conceptualized as a syndrome limited to human services employees (e.g., teachers, social workers) before it was recognized that workers from any occupational group could be affected (Maslach \& Jackson, 1981, 1986; Maslach et al., 1996). The time has come to acknowledge that the burnout syndrome is not circumscribed to the sphere of work either. Conceiving burnout as a multicontextual syndrome may provide researchers with new lines of inquiry to understand the complex interactions between stressors endured at work and in other domains of life (Bakker, 2009; Peeters, Montgomery, Bakker \& Schaufeli, 2005; Westman, Brough \& Kalliath, 2009). This may help shape a lifespan approach to burnout (Schaufeli, Maassen, Bakker \& Sixma, 2011) combining within and between-individual perspectives. Importantly, a widening of the scope to which burnout applies may also provide practitioners with new opportunities to prevent the adverse effects of chronic stress. It has been emphasized that "burnout researchers should carefully scrutinize the models that they implicitly or explicitly use to relate the measures of burnout to the construct that they seek to understand and predict" (Shirom, 2005, p. 268). This paper, as a theoretical prelude to further empirical research, was intended to serve this objective.

\section{NOTE}

1 By using the expression "Maslach's model," we neither ignore nor minimize the contributions of many researchers to the elaboration of this model (e.g., S. E. Jackson, M. P. Leiter, W. B. Schaufeli). This linguistic shortcut is only intended to promote content's concision.

\section{REFERENCES}

Ayala, E. \& Carnero, A. M. (2013). Determinants of burnout in acute and critical care military nursing personnel: A cross-sectional study from Peru. PLoS ONE, 8, e54408. 
Bakker, A. B. (2009). The crossover of burnout and its relation to partner health. Stress and Health, 25, 343-353.

Bandura, A. (1982). Self-efficacy mechanism in human agency. American Psychologist, 37, 122-147.

Beck, A. T. \& Alford, B. A. (2009). Depression: Causes and treatment (2nd edn). Philadelphia, PA: University of Pennsylvania Press.

Bekker, M., Croon, M. \& Bressers, B. (2005). Childcare involvement, job characteristics, gender and work attitudes as predictors of emotional exhaustion and sickness absence. Work \& Stress, 19, 221-237.

Bianchi, R., Boffy, C., Hingray, C., Truchot, D. \& Laurent, E. (2013) Comparative symptomatology of burnout and depression. Journal of Health Psychology, 18, 782-787.

Bourdieu, P. (2003). Pascalian meditations. Stanford, CA: Stanford University Press.

Chrousos, G. P. (2009). Stress and disorders of the stress system. Nature Reviews Endocrinology, 5, 374-381.

Chrousos, G. P. \& Gold, P. W. (1992). The concepts of stress and stress system disorders: Overview of physical and behavioral homeostasis. Journal of the American Medical Association, 267, 1244-1252.

Clays, E., De Bacquer, D., Leynen, F., Kornitzer, M., Kittel, F. \& De Backer, G. (2007). Job stress and depression symptoms in middle-aged workers - prospective results from the Belstress study. Scandinavian Journal of Work, Environment \& Health, 33, 252-259.

Clumeck, N., Kempenaers, C., Godin, I., Dramaix, M., Kornitzer, M. Linkowski, P., et al. (2009). Working conditions predict incidence of long-term spells of sick leave due to depression: Results from the Belstress I prospective study. Journal of Epidemiology and Community Health, 63, 286-292.

Cox, T., Tisserand, M. \& Taris, T. (2005). The conceptualization and measurement of burnout: Questions and directions. Work \& Stress, 19, 187-191

Dyrbye, L. N., Thomas, M. R., Huntington, J. L., Lawson, K. L., Novotny, P. J., Sloan, J. A., et al. (2006). Personal life events and medical student burnout: A multicenter study. Academic Medicine, 81, 374-384.

Farber, B. A. (1983). Stress and burnout in the human service professions. New York: Pergamon Press.

Freudenberger, H. J. (1974). Staff burnout. Journal of Social Issues, 30, $159-165$

Freudenberger, H. J. \& Richelson, G. (1980). Burnout: How to beat the high cost of success. New York: Bantam Books.

Greenglass, E. R. \& Burke, R. J. (1988). Work and family precursors of burnout in teachers: Sex differences. Sex Roles, 18, 215-229.

Hallsten, L. (1993). Burning out: A framework. In W. B. Schaufeli, C. Maslach \& T. Marek (Eds.), Professional burnout: Recent developments in theory and research (pp. 95-113). London: Taylor \& Francis.

Ishak, W., Nikravesh, R., Lederer, S., Perry, R., Ogunyemi, D. \& Bernstein, C. (2013). Burnout in medical students: A systematic review. The Clinical Teacher, 10, 242-245.

Kahn, J. P. (2008). Diagnosis and referral of workplace depression. Journal of Occupational and Environmental Medicine, 50, 396-400.

Kasl, S. V. (1978). Epidemiological contributions to the study of work stress. In C. L. Cooper \& R. L. Payne (Eds.), Stress at work (pp. $3-$ 38). Chichester: Wiley.

Kristensen, T. S., Borritz, M., Villadsen, E. \& Christensen, K. B. (2005). The Copenhagen Burnout Inventory: A new tool for the assessment of burnout. Work \& Stress, 19, 192-207.

Laborit, H. (1986). L'inhibition de l'action (2nd edn). Paris: Masson.

Landsbergis, P. A. (1988). Occupational stress among health care workers: A test of the job demands-control model. Journal of Organizational Behavior, 9, 217-239.

Leiter, M. P. (1990). The impact of family resources, control coping, and skill utilization on the development of burnout: A longitudinal study. Human Relations, 43, 1067-1083.

Lingard, H. (2004). Work and family sources of burnout in the Australian engineering profession: Comparison of respondents in dual and single-earner couples, parents, and nonparents. Journal of Construction Engineering and Management, 130, 290-298.
Lopes Cardozo, B., Gotway Crawford, C., Eriksson, C., Zhu, J., Sabin, M., Ager, A., et al. (2012). Psychological distress, depression, anxiety, and burnout among international humanitarian aid workers: A longitudinal study. PLOS ONE, 7, e44948.

Maslach, C. (1976). Burned-out. Human Behavior, 5, 16-22.

Maslach, C. (1982). Burnout: The cost of caring. Englewood Cliffs, NJ: Prentice-Hall.

Maslach, C. (1998). A multidimensional theory of burnout. In C. L. Cooper (Ed.), Theories of organizational stress (pp. 68-85). Oxford: Oxford University Press.

Maslach, C. (2003). Job burnout: New directions in research and intervention. Current Directions in Psychological Science, 12, 189-192.

Maslach, C. \& Jackson, S. E. (1981). The measurement of experienced burnout. Journal of Organizational Behavior, 2, 99-113.

Maslach, C. \& Jackson, S. E. (1986). Maslach Burnout Inventory manual (2nd edn). Palo Alto, CA: Consulting Psychologists Press.

Maslach, C., Jackson, S. E. \& Leiter, M. P. (1996). Maslach Burnout Inventory manual (3rd edn). Palo Alto, CA: Consulting Psychologists Press.

Maslach, C. \& Schaufeli, W. B. (1993). Historical and conceptual development of burnout. In W. B. Schaufeli, C. Maslach \& T. Marek (Eds.), Professional burnout: Recent developments in theory and research (pp. 1-16). New York: Taylor \& Francis.

Maslach, C., Schaufeli, W. B. \& Leiter, M. P. (2001). Job burnout. Annual Review of Psychology, 52, 397-422.

Mather, L., Blom, V. \& Svedberg, P. (2014). Stressful and traumatic life events are associated with burnout: A cross-sectional twin study. International Journal of Behavioral Medicine, doi:10.1007/ s12529-013-9381-3.

May, R. W., Sanchez-Gonzalez, M. A., Brown, P. C., Koutnik, A. P. \& Fincham, F. D. (2013). School burnout and cardiovascular functioning in young adult males: A hemodynamic perspective. Stress, 17, 79-87.

Nesse, R. M. (2000). Is depression an adaptation? Archives of General Psychiatry, 57, 14-20.

Peeters, M. C. W., Montgomery, A. J., Bakker, A. B. \& Schaufeli, W. B. (2005). Balancing work and home: How job and home demands are related to burnout. International Journal of Stress Management, 12, 43-61.

Peterson, C., Maier, S. F. \& Seligman, M. E. P. (1993). Learned helplessness: A theory for the age of personal control. New York: Oxford University Press.

Pines, A. \& Aronson, E. (1988). Career burnout: Causes and cures. New York: Free Press.

Pines, A. M., Aronson, E. \& Kafry, D. (1981). Burnout: From tedium to personal growth. New York: Free Press.

Pines, A. M., Neal, M. B., Hammer, L. B. \& Icekson, T. (2011). Job burnout and couple burnout in dual-earner couples in the sandwiched generation. Social Psychology Quarterly, 74, 361-386.

Pines, A. M. \& Nunes, R. (2003). The relationship between career and couple burnout: Implications for career and couple counseling. Journal of Employment Counseling, 40, 50-64.

Rugulies, R., Bültmann, U., Aust, B. \& Burr, H. (2006). Psychosocial work environment and incidence of severe depressive symptoms: Prospective findings from a 5-year follow-up of the Danish Work Environment Cohort Study. American Journal of Epidemiology, 163, $877-887$.

Rydmark, I., Wahlberg, K., Ghatan, P. H., Modell, S., Nygren, Å., Ingvar, M., et al. (2006). Neuroendocrine, cognitive and structural imaging characteristics of women on longterm sickleave with job stress-induced depression. Biological Psychiatry, 60, 867-873.

Salmela-Aro, K., Savolainen, H. \& Holopainen, L. (2009). Depressive symptoms and school burnout during adolescence: Evidence from two cross-lagged longitudinal studies. Journal of Youth and Adolescence, 38, 1316-1327.

Sandström, A., Rhodin, I. N., Lundberg, M., Olsson, T. \& Nyberg, L. (2005). Impaired cognitive performance in patients with chronic burnout syndrome. Biological Psychology, 69, 271-279.

Schaufeli, W. B. \& Enzmann, D. (1998). The burnout companion to study and practice: A critical analysis. London: Taylor \& Francis. 
Schaufeli, W. B., Leiter, M. P. \& Maslach, C. (2009). Burnout: 35 years of research and practice. Career Development International, 14, 204-220.

Schaufeli, W. B., Maassen, G. H., Bakker, A. B. \& Sixma, H. J. (2011). Stability and change in burnout: A 10-year follow-up study among primary care physicians. Journal of Occupational and Organizational Psychology, 84, 248-267.

Schaufeli, W. B. \& Taris, T. W. (2005). The conceptualization and measurement of burnout: Common ground and worlds apart. Work \& Stress, 19, 256-262.

Schonfeld, I. S. (2001). Stress in $1^{\text {st }}$-year women teachers: The context of social support and coping. Genetic, Social, and General Psychology Monographs, 127, 133-168.

Shirom, A. (2003). Job-related burnout: A review. In J. C. Quick \& L. E. Tetrick (Eds.), Handbook of occupational health psychology (pp. 245-264). Washington, DC: American Psychological Association.

Shirom, A. (2005). Reflections on the study of burnout. Work \& Stress, $19,263-270$.
Siegrist, J. (2008). Chronic psychosocial stress at work and risk of depression: Evidence from prospective studies. European Archives of Psychiatry and Clinical Neuroscience, 258, 115-119.

ten Brummelhuis, L. L., van der Lippe, T., Kluwer, E. S. \& Flap, H. (2008). Positive and negative effects of family involvement on workrelated burnout. Journal of Vocational Behavior, 73, 387-396.

Tennant, C. (2001). Work-related stress and depressive disorders. Journal of Psychosomatic Research, 51, 697-704.

Warr, P. (1990). The measurement of well-being and other aspects of mental health. Journal of Occupational Psychology, 63, 193-210.

Weber, A. \& Jaekel-Reinhard, A. (2000). Burnout syndrome: A disease of modern societies? Occupational Medicine, 50, 512-517.

Westman, M., Brough, P. \& Kalliath, T. (2009). Expert commentary on work-life balance and crossover of emotions and experiences: Theoretical and practice advancements. Journal of Organizational Behavior, 30, 587-595.

Received 24 December 2013, accepted 29 January 2014 